Academic Platform Journal of Engineering and Science

\title{
Havucun Boy ve Çap Verileri Kullanılarak Hacminin Hesaplanması için Matematiksel Model Geliştirilmesi
}

\author{
*1 Mustafa Nevzat Örnek, ${ }^{2}$ Humar Kahramanlı Örnek \\ ${ }^{1}$ Konya Teknik Üniversitesi Teknik Bilimler Meslek Yüksekokulu Tarım Makinaları Programı/Konya,nevzat@ selcuk.edu.tr iD \\ ${ }^{2}$ Selçuk Üniversitesi Teknoloji Fakültesi Bilgisayar Mühendisliği Bölümü / Konya, hkahramanli@ selcuk.edu.tr, \\ Araștırma Makalesi \\ Geliş Tarihi: 17.04.2018 \\ Kabul Tarihi: 28.09.2018
}

$\ddot{O} z$

Havuç, dünyada patatesten sonra en çok üretimi yapılan sebzedir. Türkiye'de havucun en çok yetiştirildiği bölge Konya iline bağlı Kaşınhanı'dır. Bu nedenle çalışmada uygulama amacı ile Kaşınhanı'nda üretilen havuçlar seçilmiştir. Toplam 464 adet Nantes türü havuç kullanılmıştır. Havuçların boyu, 5 santimetre ara ile çapları ve hacimleri ölçülmüştür. Daha sonra sunulan yöntem ile havuçların hacimleri hesaplanmış ve gerçek hacimlerle karşılaştırılmıştır. Tüm havuçlar için hesaplanan hacim ile ölçülen hacim arasındaki $\mathrm{R}^{2}$ değeri 0,9 olarak bulunmuştur. Ölçülen ve hesaplanan değerler arasında korelasyon doğrusunun eğimi 1,06 olmuştur ki, bu da ideal değere çok yakındır.

Anahtar kelimeler: Havuç, Fiziksel Özellikler, En Küçük Kareler Yöntemi, Matematiksel Model.

\section{Developing of the Mathematical Model to Calculate the Carrot Volume Using the Length and Diameter Data}

\author{
*1 Mustafa Nevzat Örnek, ${ }^{2}$ Humar Kahramanlı Örnek \\ ${ }^{1}$ Konya Technical University Vocational School of Technical Sciences Agricultural Machinery Program / Konya \\ nevzat@selcuk.edu.tr \\ ${ }^{2}$ Selçuk University Faculty of Technology Computer Engineering Department / Konya \\ hkahramanli@selcuk.edu.tr
}

\begin{abstract}
Carrot is the second most produced vegetable in the world after the potato. Most carrots grown in Turkey are grown in the Kaşınhanı of Konya province. For this reason, in this study, carrots produced in Kaşınhanı were chosen for the application purpose. A total of 464 Nantes carrots were used. The length, volume and diameters by $5 \mathrm{~cm}$ intervals of the carrots were measured. Then the volume of the carrots was calculated by the presented method and compared with the actual volumes. The $\mathrm{R}^{2}$ value between the calculated volume and the measured volume for all carrots was found as 0.9 . The correlation line between the measured and calculated values has a slope as 1.06 which is very close to the ideal value.
\end{abstract}

Keywords: Carrot, Physical Properties, Least Squares Method, Mathematical Model.

\section{GÍRIŞ}

Havuç, dünyada en çok yetiştirilen ve tüketilen kök sebzelerden biridir [1, 2]. B1, B2, B6, B12 ve C vitamini gibi besin maddelerinin yüksek olması nedeniyle insan beslenmesinde en yaygın kullanılan sebzeler arasındadır $[1,3,4]$. Havuç, vitamin A'nın yanında, yüksek $\beta$-karoten içeriğine sahip olduğu için insan tüketimi için özel bir sebzedir[1,5,6]. Anlık çorbalar, güveç, soslar, bebek maması, hazır yemekler ve sağlıklı aperatifler gibi çeşitli gıda ürünlerinde sıklıkla kullanıldığı için son yıllarda kuru havuçlar daha fazla tercih edilmektedirler [7].

Dünya nüfusunun artışıyla pazara sunulan tarım ürünlerinin sinıflandırılması ve paketlenmesi önem kazanmaya başlamıştır. Ürünün tarladan paketleme işlemi yapılacak

\footnotetext{
*1 Konya Teknik Üniversitesi TBMYO Tarım Makinaları Programı, Konya, nevzat@ selcuk.edu.tr, 0532.7264661
} 
tesislere taşınmasından sonra ürünlerin kendi özelliklerine göre sinıflandırılması gerekmektedir. Tesislerde farkl özellik gösteren birçok ürünün standartlara uygun olarak işlenmesi mümkündür. Bu tesislerde ayırma, sınıflandırma, yıkama, paketleme ve depolama gibi işlemler gerçekleştirilmektedir. Ürünün boy, çap, şekil, renk gibi özelliklerine göre sınıflandırılması, paketlenmesi ürünün piyasa değerini artırmakta, ürün kayıplarını azaltmakta, zedelenmiş ürünler ayrıldığı için raf ömürleri artmaktadır. $\mathrm{Bu}$ şekilde tarımsal ürünlerin belli standartlara uygunluğu sağlanmaktadır. Böylece elde edilen standart ürünün fiyat ve satış üstünlügü artmış olur.

Yaş sebze meyve paketleme tesislerinde, yatırım maliyeti en yüksek olan işlemi sınıflandırma aşaması oluşturmaktadır. Özellikle elektronik sinıflandırma yapılan paketleme tesislerinde hat sayısı arttıkça, yatırım maliyetleri de o oranda yükselmektedir. Paketleme tesisine sahip olan birçok firma yüksek yatırım maliyetlerinden dolayı mekanik tip sınıflandırma ünitelerini (roller tip, piyano tip, pantolon tip, tamburlu tip ve paralel yerleştirilmiş silindir tip) kullanmaktadır. Bu tip sınıflandırma üniteleri sadece boyut özelliklerine göre sinıflandırma yapabilmekte ve bu durum istenen standartları yakalamada yetersiz kalmaktadır. Ayrıca, ürünlerde oluşan mekanik hasar riski ve yeterli kapasiteye ulaşılamaması, mekanik sınıflandırma ünitelerinin olumsuzlukları olarak karşımıza çıkmaktadır. $\mathrm{Bu}$ nedenle de ülkemizde meyve ve sebzelerin ambalajlanması ve sinıflandırılmasında ileri teknolojik seviye yakalanamamakta ve bunun sonucu olarak piyasa koşullarının gerektirdiği rekabet gücü oluşamamaktadır [8].

Konya Kaşınhanı bölgesinde havuç üretimi yapan tarımsal işletmelerin bazılarında kendi yıkama ve paketleme tesisi bulunmaktadır. Yıkamadan sonra havuçlar paketleme bölümüne gelmekte ve tamamen insan iş gücü kullanılarak sınıflandırma ve paketleme işlemi yapılmaktadır. Bazı tesislerde ise mekanik sinıflandırma makineleri bulunmaktadır. $\mathrm{Bu}$ makinelerden geçirilen havuçlar sınıflandırılmakta ve daha sonra bu havuçların işçiler tarafından tekrar gözle kontrolleri yapılarak çaplarına veya uzunluklarına göre paketlere yerleştirilmektedirler. Bu paketlemeler, genellikle 5, 10 ve $15 \mathrm{~kg}$ şeklinde yapılmakta, kırık, çatallanmış, küçük boyutlu (çıtır) ve büyük boyutlu (takoz) olanlar ayrılarak paketlenmektedir. Şekil 1'de bir paketlenme tesisinde yapılan işlemler görülmektedir [8].

Meyve ve sebzelerin sınıflandırılması için üretilen makinalar gün geçtikçe artmaktadır. $\mathrm{Bu}$ makinaların bazılarında sınıflandırma amacı ile görüntü işleme kullanılmaktadır. Kameralar sebzenin görüntüsünü iki boyutlu olarak almaktadır. Bu görüntülerden, ürünlerin uzunluğu ve çapı tespit edilirken hacim ve ağırlık gibi özellikler için ek bir donanıma gerek duyulmaktadır. Bu çalışmada görüntü işleme ile elde edilecek boy ve çap özellikleri kullanılarak ek bir donanıma gerek duymadan havuç sebzesinin hacminin tespitini sağlayacak matematiksel modelin elde edilmesi amaçlanmıştır.

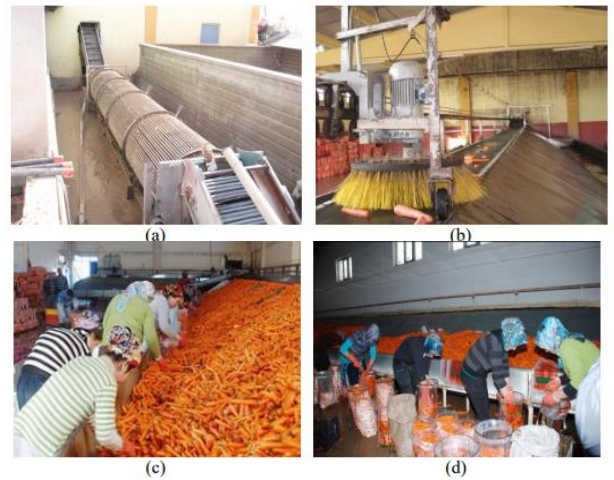

Şekil 1. Yıkama ve taşıyıcı bant (a), dağıtıcı firça (b), işçilerin havuçları seçerek paketlemesi (c, d) [8]

Aydın, Karadeniz bölgesinde yetiştirilen fındıkların fiziksel özellikleri ile ilgili bir çalışma yapmıştır. Bu çalışmada, fındık ve fındık içinin neme bağlı fiziksel özelliklerini, yani doğrusal boyutlar, birim kütle ve hacim, yuvarlaklık, yoğunluk, gözeneklilik, kopma mukavemeti ve statik katsayısı incelenmiştir [9].

Özgüven ve Vursavuş sınıflandırma aşaması için ürünlerin ebatlarının önemli olduğunu dikkate alarak, yer fıstığı için üç temel çap, geometrik çap, kütle, yuvarlaklık, yüzey alanı istatistiklerini araştırmışlardır [10].

Vursavuş ve ark. üç kiraz çeşidi olan Van, Noir De Guben ve 0-900 Ziraat'a ait uzunluk, genişlik, kalınlık, hacim, yüzey alanı, geometrik ortalama çap, meyve kütlesi, yuvarlaklık gibi çeşitli fiziksel, mekanik ve kimyasal özellikleri üzerine çalışmışlar. Üç çeşit kiraz için kütlesini tahmin etmek amacı ile çoklu doğrusal modeller geliştirmişlerdir. Kiraz çeşitleri için ekipman tasarımı ve hasat sonrası teknolojide mühendislere yararlı veriler sağlayan üç kiraz çeşidinin tüm özellikleri istatistiksel anlamda genel olarak farklı bulunmuştur. Araştırmacılar bu farklılığın bu çeşitlerin bireysel özelliklerinden, çevresel ve büyüme koşullarından kaynaklandığını belirtmişlerdir. Kiraz kütlesi ve uzunluk, genişlik, kalınlık ve geometrik ortalama çapı gibi boyut özellikleri arasındaki ilişkiyi araştırmak için deneysel verilere çoklu doğrusal bir regresyon modeli uydurulmuştur. Adımlı regresyon analizinin sonucuna göre, en iyi uyum modelinde üç tatlı kiraz çeşidi için $\mathrm{R}^{2}$ değerleri $\% 89$ ile \%91 arasında bulunmuştur [11].

Bustos-Vanegas ve ark. izotermal kavurma koşullarında kahve çekirdeğinin fiziksel özelliklerinde meydana gelen değişimi değerlendirip, kahve çekirdeği için 1sı ve kütle transfer modelleri geliştirmişler. Araştırmacılar kavrulma sıcaklığının kahve çekirdeğinin fiziksel özellikleri üzerinde etkisi olduğunu, kahve nemine bağlı olarak çekirdek yoğunluğunun doğrusal olarak azaldığını belirtmişler. Kahve çekirdeği hacim ve yüzey genişleme oranlarını modellemek için nem içeriğinin bir fonksiyonunu sunmuşlardır [12].

Munder ve ark. ayçiçeği tohumlarının farklı kalite sınıflarına hızlı ve hassas bir şekilde ayrılmasını sağlayan bir sistem oluşturdu. Bu amaçla ay çekirdeğinin fiziksel özelliklerini 
incelemiş, tohum kütlesi ile çekirdek kütlesi arasında yüksek bir pozitif korelasyon olduğunu belirlemişler. Ayrıca tohum uzunluğu, genişliği, kalınlığı ve kütlesi arasında önemsiz korelasyonlar olduğunu belirtmişlerdir [13].

Al-Garni ve ark. hava durumu verileri, güneş radyasyonu, nüfus ve kişi başına düşen gayri safi milli hasıla verilerine dayanarak Suudi Arabistan'ın doğusunda elektrik enerjisi tüketimi için bir model geliştirmişlerdir. Modeli üretmek için en küçük kareler yöntemi kullanılmıştır [14].

Alfares ve Nazeeruddin bir yıl için günlük maksimum yük tahminini yapmak amacı ile en küçük kareler yöntemini kullandılar. Çalışma sadece iş günlerini değil, tatilleri de kapsamaktadır. Farklı mevsimlerde yükü etkileyen faktörleri de göz önüne almak için yaz mevsiminde kullanılan açıklayıcı değişkenlere ek olarak, kış mevsiminde ortalama rüzgar soğuma faktörü açıklayıcı bir değişken olarak eklenmiştir [15].

Reeder ve ark. çok nokta Dixon yağ-su ayrımı için yeni bir yaklaşım sunmuştur. Su ve yağ görüntüsünü ayrıştıran yinelemeli bir lineer en küçük kareler yöntemi kullanılarak, yüksek bir sinyal-gürültü oranı ve su ile yağın üniform ayrılması elde edilmiştir [16]. Beauducel ve Herzberg doğrulayıcı faktör analizi için en küçük kareler yöntemi kullanmışlar. Çalışma dört farklı numune boyutu için (250, $500,750,1000)$, dört farklı değişken sayısı $(5,10,20$ ve 40 ile 1, 2, 4, ve sırasıyla 8 latent faktör) ve değişskenlerdeki beş sayı kategorisi $(2,3,4,5$ ve 6$)$ üzerinde yapılmıştır [17].

\section{MATERYAL METOD}

\subsection{Materyal}

Araştırmada, Konya Kaşınhanı Bölgesinde yaygın olarak üretimi yapılan Nantes (Daucus carota L.) çeşidi havuçlar kullanılmıştır. Örnek olarak 2017 Eylül ayı içinde toplam 500 adet havuç rasgele olarak alınmıştır.

Havuç, yaklaşık \%86-93 (yaş baz) su muhtevasına sahip yüksek nemli bir gıda çeşididir. Bu nedenle nem kaybı havucun fiziksel özelliklerinin kaybına sebep olur ve taze görünümünü kaybetmesi gerçekleşir. Kalite kaybını azaltmak için, havuç uygun bir sıcaklık ve neme sahip bir ortamda saklanmalı veya uygun kurutma yöntemleriyle dehidrate edilmelidir [3].

$\mathrm{Bu}$ nedenle çalışmada tüm ölçümler $24^{\circ} \mathrm{C}$ 'lik bir oda sıcaklığında ve aynı gün içinde gerçekleştirilmiştir. Alınan havuçlardan ezilen, çürük, bozuk, kırık olanlar değerlendirme dışı bırakılmıştır. Toplam 464 adet havuç için aynı gün içinde ve aynı ortamda ölçümler yapılmıştır.

Havucun fiziksel özelliklerini belirlemek için sırası ile;

- Uzunluğu ölçmek için $50 \mathrm{~cm}$ boyunda $1 \mathrm{~mm}$ hassasiyetinde çelik cetvel (=boyu mm);
- Çapı ölçmek için 0,1 mm'lik bir hassasiyete sahip Stainless Hardere marka dijital kumpas (=çap mm);

- Kütlesini ölçmek için 0,001 g hassasiyette hassas bir elektronik terazi;

- Hacimleri ölçmek için $100 \mathrm{ml}$ ve $200 \mathrm{ml}$ lik dereceli silindirler kullanılmıştır.

Önce havuçlar sıra ile düz bir zemine konulup çelik cetvel ile boyu, cetvel üzerindeki işaretli $50 \mathrm{~mm}$ aralıklarla ölçülmüştür (Şekil 2). Havucun çapını ölçmek için kumpas kullanılmıştır. Elde edilen fiziksel özelliklere ait verilerle ilgili istatistiki değerler Çizelge 1'de, frekans dağılım grafiği Şekil 3'te görülmektedir.

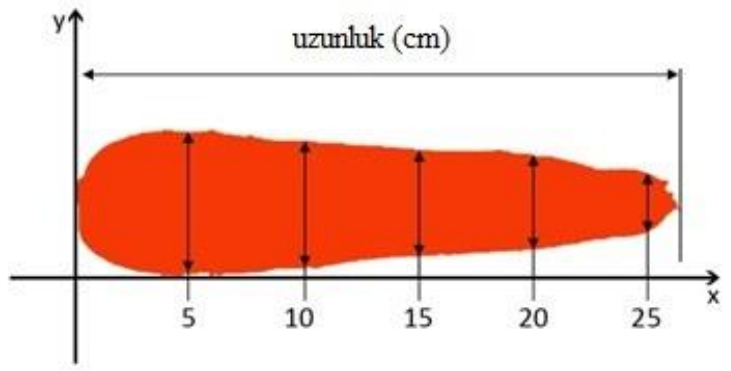

Şekil 2. Yıkama ve taşıyıcı bant (a), dağıtıcı firça (b), işçilerin havuçları seçerek paketlemesi (c, d) [8]

Çizelge 1. İncelenen havuçların fiziksel özellikleri ile ilgili istatistiki değerler

\begin{tabular}{|c|c|c|c|c|c|c|c|}
\hline & $\begin{array}{c}0 \\
\text { cm'de } \\
\text { yarıça } \\
\text { p }\end{array}$ & $\begin{array}{c}5 \\
\text { cm'de } \\
\text { yarıça } \\
\text { p }\end{array}$ & $\begin{array}{c}10 \\
\text { cm'de } \\
\text { yarıça } \\
\text { p }\end{array}$ & $\begin{array}{c}15 \\
\text { cm'de } \\
\text { yarıça } \\
\text { p }\end{array}$ & $\begin{array}{c}20 \\
\text { cm'de } \\
\text { yarıça } \\
\text { p }\end{array}$ & $\begin{array}{l}\text { Boy } \\
(\mathrm{cm})\end{array}$ & $\underset{(\mathrm{ml})}{\operatorname{Hacim}}$ \\
\hline & $(\mathrm{cm})$ & $(\mathrm{cm})$ & $(\mathrm{cm})$ & $(\mathrm{cm})$ & $(\mathrm{cm})$ & & \\
\hline Minimum & 1,04 & 0,66 & 0 & 0 & 0 & 7 & 11 \\
\hline $\begin{array}{r}\text { Maksimu } \\
\mathrm{m}\end{array}$ & 2,44 & 2,41 & 1,95 & 1,62 & 1,42 & 24 & 247 \\
\hline Ortalama & 1,62 & 1,51 & 1,19 & 0,81 & 0,17 & $\begin{array}{c}17,6 \\
1\end{array}$ & $\begin{array}{c}89,6 \\
9\end{array}$ \\
\hline St. sapma & 0,26 & 0,27 & 0,29 & 0,44 & 0,34 & 2,85 & $\begin{array}{c}36,4 \\
5\end{array}$ \\
\hline
\end{tabular}

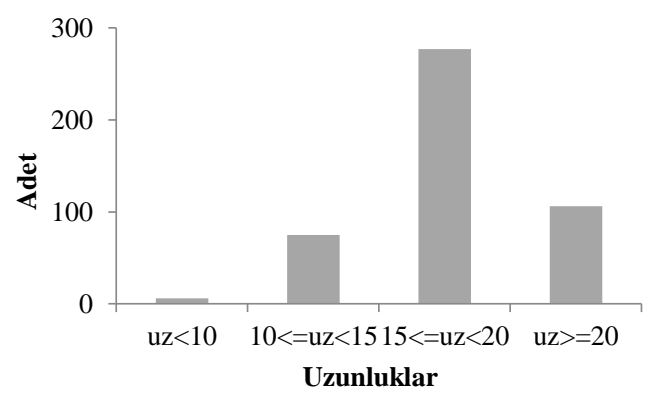

Şekil 3. Havuç uzunluklarının frekans dağılımı Verilen havuçlarda istatistiklere ek olarak uzunluğu 10 cm'nin üstünde 458 adet, 15 cm'den fazla 383 adet, 20 cm'den fazla 106 adet havuç bulunmaktadır.

\subsection{Yöntem}

Havucun hacminin matematiksel yöntemlerle hesaplanabilmesi için en küçük kareler yaklaşımı ve dönel 
cismin hacminin hesaplanması için integral yöntemi kullanılmıştır.

\section{a. Polinom için en küçük kareler yaklaşımı}

$k$. dereceden polinom genel olarak;

$y=\sum_{i=0}^{n} a_{i} x^{i}=a_{0}+a_{1} x+a_{2} x^{2}+\cdots+a_{n} x^{n}$

biçimindedir. $n$. dereceden eğri uydurma problemini çözmek, $(n+1)$ adet $a_{i}, i=0,1, \ldots, n$ katsayısı bulmak demektir. Eğri uydurma probleminde her nokta için hata

$h_{k}=y_{k}-\sum_{i=0}^{n} a_{i} x_{k}^{i}$

hatanın karesi ise;

$h_{k}^{2}=\left[y_{k}-\sum_{i=0}^{n} a_{i} x_{k}^{i}\right]^{2}$

ile hesaplanır.

Hataların kareleri toplamı ise aşağıdaki gibi hesaplanır;

$H=\sum_{k=1}^{N} h_{k}^{2}$

Burada, $N$ noktaların sayıdır. Hataların kareleri toplamı $H^{\prime}$ nin kısmi türevleri aşağıdaki gibi hesaplanır.

$\frac{\partial(H)}{\partial a_{0}}=-2 \sum_{k=1}^{N} h_{k}=-2 \sum_{k=1}^{N}\left(y_{k}-\sum_{i=0}^{n} a_{i} x_{k}^{i}\right)$
$\frac{\partial(H)}{\partial a_{1}}=-2 x \sum_{k=1}^{N} h_{k}=-2 x \sum_{k=1}^{N}\left(y_{k}-\sum_{i=0}^{n} a_{i} x_{k}^{i}\right)$

$\frac{\partial(H)}{\partial a_{n}}=-2 x^{n} \sum_{k=1}^{N} h_{k}=-2 x^{n} \sum_{k=1}^{N}\left(y_{k}-\sum_{i=0}^{n} a_{i} x_{k}^{i}\right)$

En küçük kareler yaklaşımında hataların minimum olması için hataların karelerinin sıfıra eşitlenmesi gerekir. Bunun sonucu olarak aşağıdaki denklem sistemi elde edilir.

$a_{0} N+a_{1} \sum_{i=1}^{N} x_{i}+\cdots+a_{n} \sum_{i=1}^{N} x_{i}^{n}=\sum_{i=1}^{N} y_{i}$

$a_{0} \sum_{i=1}^{N} x_{i}+a_{1} \sum_{i=1}^{N} x_{i}^{2}+\cdots+a_{n} \sum_{i=1}^{N} x_{i}^{n+1}=\sum_{i=1}^{N} x_{i} y_{i}$

$a_{0} \sum_{i=1}^{N} x_{i}^{n}+a_{1} \sum_{i=1}^{N} x_{i}^{n+1}+\cdots+a_{n} \sum_{i=1}^{N} x_{i}^{2 n}=\sum_{i=1}^{N} x_{i}^{n} y_{i}$

$\mathrm{Bu}$ sistem Vandermonde matrisi biçiminde ifade edilirse,

$\left[\begin{array}{cccc}1 & x_{1} & \cdots & x_{1}^{n} \\ 1 & x_{2} & \cdots & x_{2}^{n} \\ \vdots & \vdots & \ddots & \vdots \\ 1 & x_{N} & \cdots & x_{N}^{n}\end{array}\right]\left[\begin{array}{c}a_{0} \\ a_{1} \\ \vdots \\ a_{n}\end{array}\right]=\left[\begin{array}{c}y_{1} \\ y_{2} \\ \vdots \\ y_{N}\end{array}\right]$ elde edilir. Bu denklemler çözüldüğünde elde edilen $a_{i}, i=$ $0,1, \ldots, n$ değerleri (1) denkleminde yerine yazılırsa eğri denklemi elde edilmiş olur.

\section{b. Hacim hesaplama}

$y=f(x)$ eğrisinin $x$ ekseni etrafında $360^{\circ}$ döndürülmesi ve $x=a$ ve $x=b$ doğruları arasında oluşan cismin hacmi;

$y=\pi \int_{a}^{b}[f(x)]^{2} d x$

ile hesaplanır (Şekil 4). (1) denklemi burada yazılırsa;

$y=\pi \int_{0}^{b}\left[\sum_{i=0}^{n} a_{i} x^{i}\right]^{2} d x$

elde edilir. Son elde edilen formül kullanılarak bir havucun hacmi hesaplanabilir.

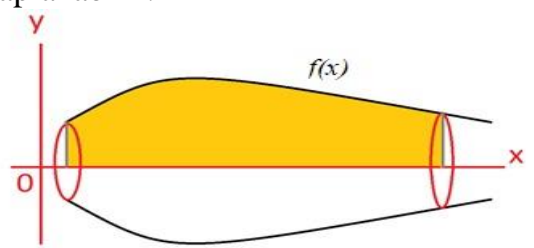

Şekil 4. Eğrinin $x$ ekseni etrafında dönmesi sonucu elde edilen cisim

\section{BULGULAR}

Çalışmanın amacı kesit yarıçapları ve uzunluğu belli olan havucun hacminin hesaplanmasıdır. Bu amaçla havucun koordinat sistemine oturtulduğu varsayılarak önce en küçük kareler yöntemi uygulanmış ve havucun kenarı için eğri denklemi oluşturulmuştur. Eğri olarak üçüncü dereceden polinom fonksiyonu tercih edilmiştir. Oluşturulan eğri (9) denklemine uygulanarak havucun yaklaşık hacmi hesaplanmıştır.

Örnek olarak 254 numaralı havucun ölçülen bilgileri Çizelge 2'nin 1. satırında görülmektedir.

Çizelge 2. Örnek olarak seçilen bir havucun fiziksel özellikleri.

\begin{tabular}{rcc}
\hline & Ölçülen & Hesaplanan \\
\hline 0 cm'de yarıçap $(\mathrm{cm})$ & 1,7325 & 1,740786 \\
$5 \mathrm{~cm}$ 'de yarıçap $(\mathrm{cm})$ & 1,68 & 1,646857 \\
$10 \mathrm{~cm}$ 'de yarıçap $(\mathrm{cm})$ & 1,3125 & 1,362214 \\
$15 \mathrm{~cm}$ 'de yarıçap $(\mathrm{cm})$ & 1,0765 & 1,043357 \\
$20 \mathrm{~cm}$ 'de yarıçap $(\mathrm{cm})$ & 0,8385 & 0,846786 \\
Uzunluk $(\mathrm{cm})$ & 21,1 & \\
Hacim $(\mathrm{ml})$ & 120 & 121,14 \\
\hline
\end{tabular}

$\mathrm{Bu}$ havucun yarıçaplarına göre eğri uydurulduğunda (10) fonksiyonu elde edilmiştir.

$f(x)=0,000209 * x^{3}-0,00694 * x^{2}+0,010719 * x+$ 1,740786

(10) fonksiyonu uygulandığında örnek havuç için elde edilen yarıçaplar Çizelge 2'nin 2. satırında görülmektedir. Şekil 5. 
ve Şekil 6. incelendiğinde elde edilen eğrinin havucu başarılı bir biçimde temsil ettiği görülmektedir. (10) fonksiyonu (9)'a uygulandığında;

$y=\pi \int_{0}^{21,1}\left[0,000209 * x^{3}-0,00694 * x^{2}+0,010719 *\right.$ $x+1,740786]^{2} d x$

elde edilir. Gerekli işlemler yapıldıktan sonra örnek havucun hacmi $121,14 \mathrm{~cm}^{3}$ olarak hesaplanmıştır ki, bu da havucun hacminin \%0.05 hata ile hesaplanmış olduğu anlamına gelmektedir.

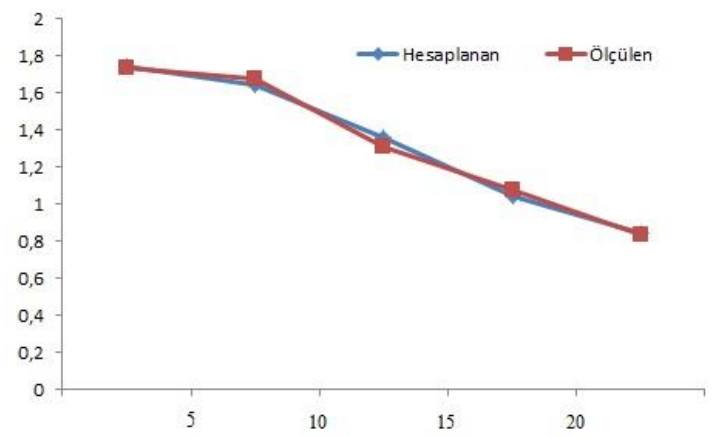

Şekil 5. Örnek havuç için ölçülen ve hesaplanan değerlerin karşılaştırılması

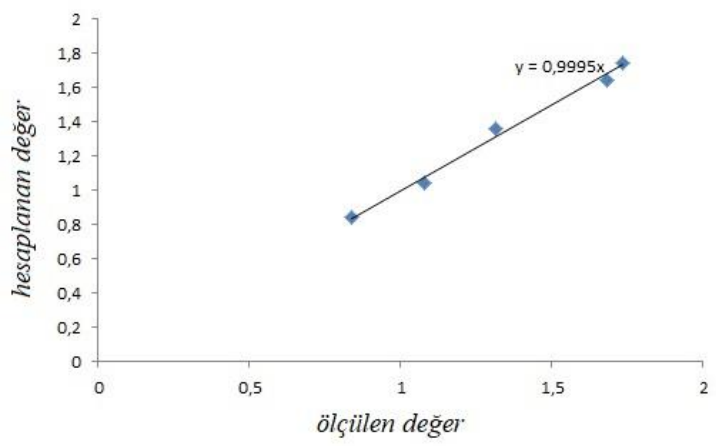

Şekil 6. Örnek havuç için ölçülen ve hesaplanan değerler arasındaki korelasyon

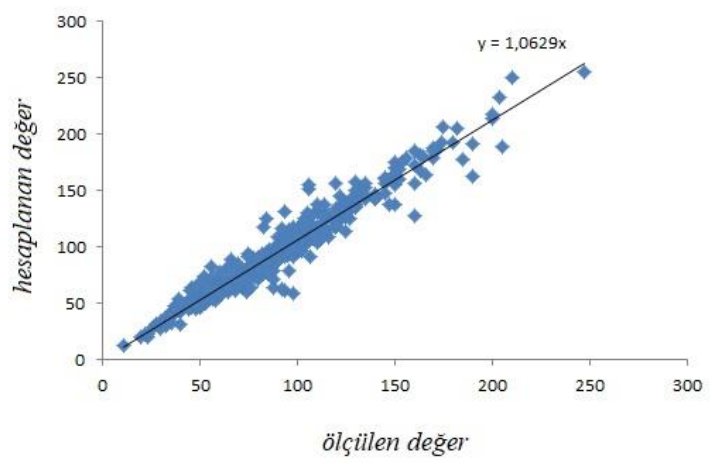

Şekil 7. Tüm havuçlar ölçülen ve hesaplanan değerler arasındaki korelasyon

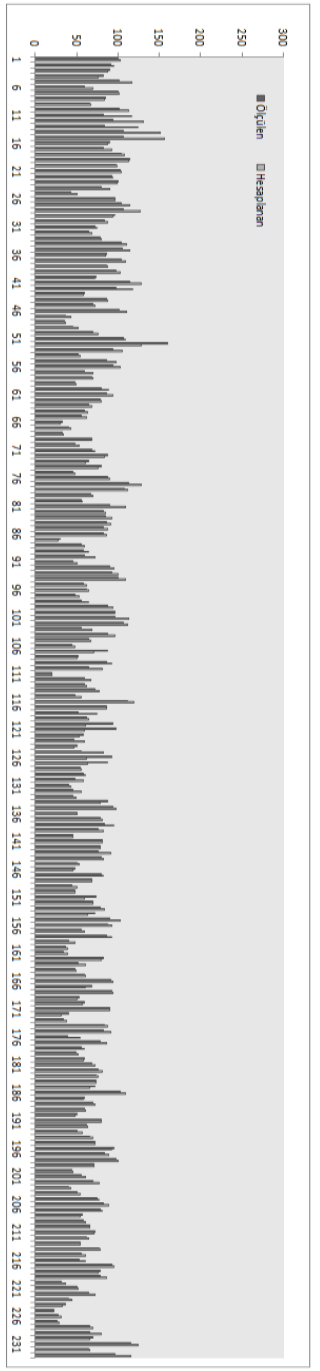

(a) ilk 232 havuç

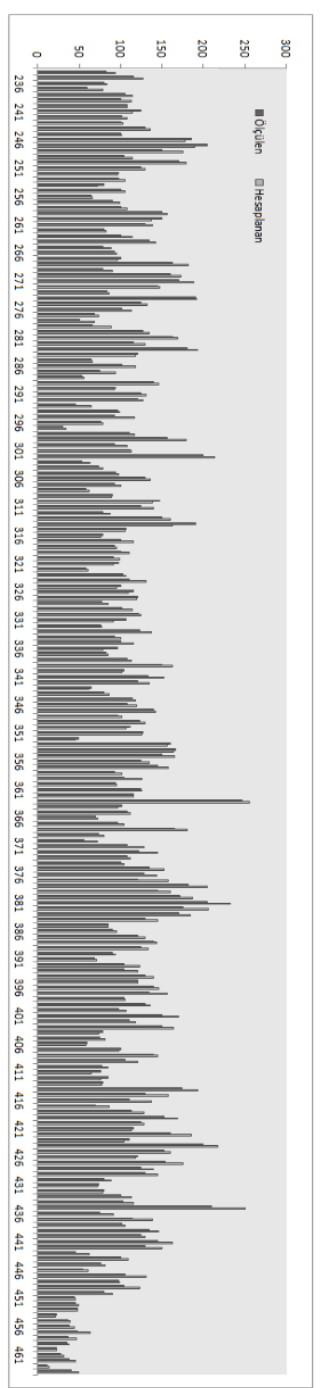

(b) diğer 232 havuç
Şekil 8. Tüm havuçlar için ölçülen ve hesaplanan değerlerin karşılaştırılması

Tüm havuçlar için elde edilen sonuçlar incelendiğinde (Şekil 7) (9) denkleminin başarılı sonuçlar ürettiği görülmektedir. İdeal tahminde $\mathrm{R}^{2}$ değerinin ve korelasyon doğrusu eğiminin 1 olması gerekir. Çalışmada tüm havuçlar için hesaplanan hacim ile ölçülen hacim arasındaki $\mathrm{R}^{2}$ değeri 0,9 olarak bulunmuştur. Şekil 8 'den de görüldüğü gibi ölçülen ve hesaplanan değerler arasında korelasyon doğrusunun eğimi 1,06 olmuştur ki, bu da ideal değere çok yakındır.

\section{SONUÇLAR}

Çalışmada kesit yarıçapları ve uzunluğu bilinen bir havucun hacminin hesaplanması amaçlanmıştır. Bunun için 464 havuç üzerinde çalışma yapılmıştır. Sonuç olarak önerilen yöntemin havuçların hacmini hesaplama konusunda başarılı olduğu gözlemlenmiştir. Çalışma görüntü işleme ile havuç 
sınıflandırma çalışmalarının ilk adımı olarak yapılmıştır. Önerilen yöntem kullanılarak görüntüsü alınan bir havucun ek bir cihaza gerek duymadan hacminin hesaplanabileceği gösterilmiştir. Ayrıca yöntemin salatalık, domates, patates, elma, armut, şeftali gibi meyve ve sebzelere de uygulanabileceği düşünülmektedir.

\section{KAYNAKÇA}

[1] W.G. Lin, B. Xu, B. Wei, R. Zeng, "Low frequency ultrasound pretreatment of carrot slices: Effect on the moisture migration and quality attributes by intermediatewave infrared radiation drying", UltrasonicsSonochemistry, vol. 40, pp. 619-628, 2018. https://doi.org/10.01016/j.ultsonch.2017.08.005.

[2] Z.G. Chen, X.Y. Guo, T. Wu, "A novel dehydration technique for carrot slices implementing ultrasound and vacuum drying methods Ultrason. Sonochem", vol.3, pp. 2834, 2016.

[3] J. Frias, E. Peñas, M. Ullate, C. Vidal-Valverde, "Influence of drying by convective air dryer or power ultrasound on the vitamin $\mathrm{C}$ and beta-carotene content of carrots", J. Agric. Food Chem., vol. 58, pp:10539-10544, 2010.

[4] K. Gornicki, A. Kaleta, "Drying curve modelling of blanched carrot cubes under natural convection condition", Journal Food Engeneer, vol. 82, pp.160-170, 2007.

[5] B. Bao, K.C. Chang, "Carrot juice color, carotenoids, and nonstarchy polysaccharides as affected by processing conditions" Journal of Food Science, vol.59, pp.11551158,1995 .

[6] J.L. Bureau, R.J. Bushway, "HPLC determination of carotenoids in fruits and vegetables in the United States", Journal of Food Science, vol. 51(1), pp.128-130, 1986.

[7] M. Nowacka, M. Wedzik, "Effect of ultrasound treatment on microstructure, colour and carotenoid content in fresh and dried carrot tissue", Applied Acoustics vol. 103, pp.163-171, 2016.

[8] M.N. Örnek, "Havuç Sınıflandırmada Gerçek Zamanlı Görüntü İşleme Makinası Tasarımı ve Bazı Mekanik Sınıflandırma Makinaları ile boylama etkinliklerinin karşılaştırılması”, Doktora Tezi, Selçuk Üniversitesi Fen
Bilimleri Enstitüsü, Tarım Makinaları Anabilim Dalı, Konya,2014.

[9] C. Aydin, "Physical Properties of Hazel Nuts, Biosystems Engineering”, vol. 82(3), pp. 297-303,2002.

[10] F. Özgüven, K. Vursavuş, "Some physical, mechanical and aerodynamic properties of pine (Pinus pinea) nuts", Journal of Food Engineering, vol. 68, pp.191-196, 2005.

[11] K. Vursavuş, H. Kelebek, S. Selli, "A study on some chemical and physico-mechanic properties of three sweet cherry varieties (Prunus avium L.) in Turkey", Journal of Food Engineering, vol.74(4), pp.568-575, 2006. https://doi.org/10.1016/j.jfoodeng.2005.03.059

[12] J.D. Bustos-Vanegas, P.C. Corrêa, M.A. Martins, F.M. Baptestini, R.C. Campos, G.H.H. Oliveira, E.H.M. Nunes, "Developing predictive models for determining physical properties of coffee beans during the roasting process, Industrial Crops and Products", Industrial Crops and Products, 2017.

doi: https://doi.org/10.1016/ j.indcrop.2017.12.015

[13] S. Munder, D. Argyropoulos, J. Muller, "Class-based physical properties of air-classified sunflower seeds and kernels", Biosystems Engineering, vol.164, pp.124-134. 2017.

[14] A. Z. Al-Garni, Z. Ahmed, Y. N. Al-Nassar, S. M. Zubair and A. AL-Shehri, "Model for electric energy consumption in Eastern Saudi Arabia". Energy Sources, vol. 19, pp. 325-334, 1997.

[15] H.K. Alfares, M. Nazeeruddin, "Regression-based methodology for daily peak load forecasting". Proceedings of the 2nd International Conference on Operations and Quantitative Management, Ahmedabad, India, pp. 468-471. 1999.

[16] S.B. Reeder, Z. Wen, H. Yu, A.R. Pineda, G.E. Gold, M. Markl, N. J. Pelc, "Multicoil Dixon chemical species separation with an iterative least-squares estimation method, Magnetic Resonance in Medicine”, vol. 51(1), pp. 35-45, 2004.

[17] A. Beauducel, P.Y. Herzberg, "On the Performance of Maximum Likelihood Versus Means and Variance Adjusted Weighted Least Squares Estimation in CFA, Structural Equation Modeling”, vol. 13(2), pp. 186-203, 2006. 